\title{
INFORMATION SYSTEMS SUCCESS IN SMALL AND MEDIUM ENTERPRISES: AN EVALUATION BY AUSTRALIAN PUBLIC ACCOUNTANTS
}

\author{
Dieter Fink \\ School of Management Information Systems \\ Edith Cowan University \\ Pearson Street \\ Churchlands WA 6018 \\ Australia
}

\begin{abstract}
Traditionally, the success of Information Systems (IS) has been studied in the context of large organisations with a focus on systems that have been developed inhouse. Most businesses, however, are small and medium enterprises (SMEs), and they have increasingly adopted packaged application software. To evaluate their success we examined two research variables, namely user practices and design features. The evaluation was done by public accountants who deal with SMEs as clients and are most likely to have well-developed opinions on the use of packaged software. In general, they rated small/medium accounting software packages as satisfactory with some notable exceptions. The installation phase of packages is not very well managed. Packages appear to lack a number of important control features which, considering the lack of internal IS expertise in SMEs, could result in malfunctions of their accounting systems. The study identifies better documentation and user education as ways to overcome perceived deficiencies.
\end{abstract}

\section{INTRODUCTION}

Traditionally, the success of Information Systems (IS) has been studied in the context of large organisations with a focus on systems that have been developed inhouse. Most businesses, however, are small and medium enterprises (SMEs), and they have increasingly adopted packaged application software to meet their information processing requirements. Furthermore, due to the small number of employees, SMEs depend on outside support for the success of their IS activities. Studies in the smal/medium packaged systems domain are now emerging. For example, Gray (1991) investigated the incongruences between accounting professionals when assisting small organisations in the selection of Accounting Information Systems (AIS). Ponemon and Nagoda (1990) investigated the perceptions of team members during packaged AIS implementation.

Our study extends this research by investigating user practices and design features of installed small/medium packaged accounting software. At the commencement of our research we believed, as did Nazem (1990), "that some sense of maturity with respect to the use of computers is emerging in small businesses" (p. 100) and that it is time to evaluate the use and design of packages that have been operating for a while. We chose public accountants acting as advisors to SMEs to perform this evaluation. The study's primary aim was to provide feedback of contemporary adequate and inadequate user practices and design features to small/medium accounting package users and developers.

\section{BACKGROUND LITERATURE}

For the present study, three areas of IS research are particularly relevant. They are information systems success, the use and design of small/medium accounting packages, and public accountants involvement with packaged software.

\section{The notion of information systems success}

Interest in what constitutes the "success" of Information Systems has mainly focused on large computer systems. Typically, factor research is carried out which "deals with the influence of static organisational abstractions and technical system quality upon successful implementation." (Cerveny and Sanders, 1986, p. 192) During the 1980s research focused on the criteria of system quality, information quality, use, user satisfaction, individual impact and organisational impact (DeLone and McLean, 1992). In recent years, IS success variables have included system impact on strategic direction, the integration of the IS plan with the corporate plan, the quality of information outputs, contribution to organisational performance, and the identification and integration of new technologies (Saunders and Jones, 1992).

Studies in the smailer systems area have found factors determining IS success to include consultant effectiveness, vendor support, IS experience, sufficiency of financial resources, CEO support, and user participation (Yap et al, 1992). Furthermore, there is evidence that Information Technology (IT) growth in small-firm computing is strongly motivated by the owner's enthusiasm towards computing and inhibited by lack 
of IS knowledge, lack of managerial time, poor support, and limited financial resources (Cragg and King, 1993).

It is generally acknowledged that the IS success notion is difficult to operationalise. The key reason for this is that over time measures have changed to reflect first, changes in IT and second, differing expectations of the role of IS within organisations. Formal measurement frameworks that have emerged in recent years include the IS Success Model (Delone and McLean, 1992), the IS Function Performance Evaluation Model (Saunders and Jones, 1992) and the Goal/System Resource model (Sethi et al, 1993). The use of different measurement frameworks make comparisons between studies difficult, if not impossible, and render findings ambiguous and confounding. Sethi et al (1993) concluded that the literature has not yet build a critical mass of research in the area. Further developments and refinements of measures of IS performance are needed according to Saunders and Jones (1992) before IS success can be measured precisely.

Our study adopted the model of successful IS implementation provided by Cerveny and Sanders (1986). This model identifies factors that lead to the improved quality of implementation which contributes to successful implementation outcomes. We examined the left side of the model, namely designer characteristics (in the form of package design features) and user characteristics (in the form of package user practices).

\section{User practices and design features of accounting packages}

Whilst computer hardware is becoming reliable and mature, the software industry remains volatile. This is a potential concern to SMEs who rely heavily on off-the-shelf rather than inhouse developed software, particularly for basic accounting applications (Nazeem, 1990). The opportunity for modification is usually limited in extent and to the time of implementation since in order to protect future sales the vendor rarely sells the source code for the program. "Therefore, with less opportunity to modify acquired software, the potential for failures may be heightened for smaller organizations." (Gray, 1991, p. 19) Once prewritten application software is operational, SMEs may have to be satisfied with the design features of packages provided for them. Yet, Nazeem (1990) found that off-the-shelf software users in small businesses were satisfied with the flexibility of their systems and their ability to expand it. Opinions regarding performance and reliability of application software were also favourable. It appears therefore that packaged software can be flexible and, mostly through the setting of parameters, is capable of being configured to more closely suit the needs of users. Whereas design features are largely given, user practices are determined by the enterprise's internal practices and preferences. Nazeem (1990) found that users of packaged software in small business were familiar with their systems and achieving competence, and appeared to be satisfied with the security offered by packages. Those that were concerned with security tended to develop their own inhouse IS. It appears that in small business particular importance is placed on the software attributes of performance and audit trail (Gray, 1991).

\section{Potential support offered by public accountants}

The 1980s provided SMEs with the opportunity to introduce low-cost computer hardware and packaged systems. The following years yielded "a picture of growth and stagnation in small-firm computing. While many firms had experienced growth in the number and type of IT applications, there had been little change with respect to the management of IT in small firms." (Cragg and King, 1993, p. 57) The lack of internal expertise points to the need to use external support from vendors and consultants, including public accountants, to ensure the continued effectiveness of IS. Package suppliers appear to have recognised this by providing interface functions within packages that allow third parties to develop specialised modules to meet particular functional and industry requirements.

In Yap et al's (1992) study, 53\% of the small Singaporean businesses in the sample engaged consultants to assist in implementation and their support significantly affected information systems success. The contribution of consultants is dependent on the quality of the consultant. Clients in Yap et al's (1992) study described an ineffective consultant as lacking specific experience, not considering future expansion, seeming unaware of actual user requirements, and ignoring specific aspects of the business. When consultants are involved in implementation they need to have agreement among themselves since it has been found that a strong relationship exists between incongruences within the implementation team and IS failures (Ponemon and Nagoda, 1990).

In Gray's (1991) study a large number of accounting professionals had both user and advisor experiences. This led to the conclusion that in the small-organisation domain, "because of the widespread distribution of microcomputers, advisors may tend to be users of their own AIS. This may indicate that small AIS advisors will be more sensitive to the users' needs than large AIS advisors." (p 32) However, there are indications of a 
negative attitude by small firms towards consultants. A recent study found that small firms appear to have poor relationships with IT specialists and also show little desire for the situation to change (Cragg and King, 1993).

\section{THE STUDY}

Our research took the approach that public accountants who deal with SMEs as clients in the capacity of auditors, accountants, advisors or consultants are most likely to have well-developed opinions on the use of small/medium pre-written packaged accounting software. We were influenced in this approach by the finding that the majority of small firms rely on external support to meet their IT requirements (Yap et al, 1992) and that IT management in small firms is not sophisticated (Cragg and King, 1993). Furthermore, it appears that many advisors have experience in small-business computing themselves (Gray, 1991). We selected two variables of small/medium accounting packages, namely user practices and design features, for our research. The variables play an important part in Cervany and Sanders' (1986) model of successful IS implementation discussed in an earlier section. Below follows a discussion of the research process and associated validity and reliability considerations.

\section{Research design and conduct}

We found that the selection of the attributes against which the two research variables could be evaluated provided many choices. As stated by Gray (1991) "selecting the appropriate attribute subset becomes a significant decision in itself" (p. 21). Zeleny (1982), quoted in Gray, 1991) defines the requirement of attributes as: Attributes-descriptors of objective reality. They may be actual objectives traits, or they may be subjectively assigned traits, but they must be perceived as characteristics of the object in the "outside" world. We decided to maintain symmetry between the two main research attributes, user practices and design features, and not to make the questionnaire so lengthy that it would cause a lack of response. Consequently, the user practices section contained six subsets and design features section seven subsets. Within each of these subsets (or categories) are three items except for two subsets with four items. Altogether user practices consisted of 20 items and design features of 21 items. Details of categories and items compiled by us are shown in Tables 3 and 4. The construction of the questionnaire was validated externally as discussed later in the article under validity and reliability testing.

The research was supported by the Institute of Chartered Accountants in Australia (ICAA). Together with the Institute's officials we selected the members to be invited to participate in the study on the basis of their fields of interest, as contained in the membership data base of the ICAA. The interest fields selected were auditinformation systems \& control; audit- external; business services; computer services; information technologyconsulting; and small business. The questionnaire was sent to Chartered Accountants in public practice with the position of Manager and one of the above fields of interest. The importance of the project was conveyed in the accompanying covering letter which was written by the ICAA. The covering letter stated the desirability of the research, namely that it would assist to establish and maintain the ICAA's "leadership position on the application of IT to business".

We selected managers as subjects because they typically are required to maintain a "hands-on" relationship with clients whilst maintaining an overall perspective of the engagement. They were requested to pass the survey to an appropriate person within their firm should they be unable to complete the survey themselves. The member data base of the ICAA identified 470 managers with the relevant fields of interest. Of those, 53 were overseas, leaving 417 recipients of the questionnaire. Altogether 135 questionnaires $(32.1 \%)$ were returned. Of those 23 questionnaires were unsatisfactorily completed and rejected for further processing. This left 112 useable responses yielding a response rate of $26.8 \%$.

A breakdown of the responses by job function identified four major groupings: management consultants, business advisors, auditors, and accounting services staff. They accounted for 103 of the 112 responses available for processing. The remaining two groupings, taxation advisory and business recovery, contained only three responses each, whilst the job functions of a further three responses were not specified and are therefore unknown. Table 1 provides demographic data for both the total responses $(n=112)$ and for the four major groupings $(\mathrm{n}=103)$. 
Table 1: Demographic data of respondents

\begin{tabular}{lllll} 
& $\mathrm{N}$ & $\%$ & $\mathrm{~N}$ & $\%$ \\
\hline Job Functions & & & & \\
Management Consulting & 21 & 18.7 & 21 & 20.4 \\
Business Advisory & 33 & 29.5 & 33 & 32.0 \\
Taxation Advisory & 3 & 2.7 & & \\
Auditing & 35 & 31.2 & 35 & 34.0 \\
Accounting Services & 14 & 12.5 & 14 & 13.6 \\
Business Recovery & 3 & 2.7 & & \\
Unknown & 3 & 2.7 & & \\
$\quad$ Total & 112 & 100.0 & 103 & 100.0 \\
Positions held & & & & \\
Partner & 22 & 19.6 & 19 & 18.4 \\
Director & 9 & 8.0 & 8 & 7.8 \\
Manager & 72 & 64.3 & 67 & 65.0 \\
Senior & 6 & 5.4 & 6 & 5.8 \\
Junior & 1 & .9 & 1 & 1.0 \\
Other & 2 & 1.8 & 2 & 2.0 \\
$\quad$ Total & 112 & 100.0 & 103 & 100.0 \\
Age Distribution & & & & \\
20 - 25 & 7 & 6.3 & 6 & 5.8 \\
26 - 35 & 74 & 66.0 & 69 & 67.0 \\
36 - 45 & 25 & 22.3 & 22 & 21.4 \\
46 - 55 & 6 & 5.4 & 6 & 5.8 \\
$\quad$ Total & 112 & 100.0 & 103 & 100.0 \\
State & & & & \\
New South Wales & 44 & 39.3 & 42 & 40.8 \\
Victoria & 25 & 22.3 & 22 & 21.3 \\
Queensland & 17 & 15.2 & 16 & 15.5 \\
Western Australia & 12 & 10.7 & 11 & 10.7 \\
South Australia & 8 & 7.1 & 6 & 5.8 \\
Tasmania & 3 & 2.7 & 3 & 2.9 \\
Northern Territory & 1 & .9 & 1 & 1.0 \\
Overseas & 2 & 1.8 & 2 & 2.0 \\
$\quad$ Total & 112 & 100.0 & 103 & 100.0 \\
\hline & & & & \\
\hline & & & &
\end{tabular}

As seen from the above table, most participants in the study described themselves at the manager level, they were most often in the age bracket 26-35 years, and New South Wales was the most common location of respondents.

\section{Validity and reliability}

We sought construct validity of our questionnaire by requesting members of the IT chapter of the ICAA to review of our draft questionnaire. Based on the comments received, the questionnaire was revised in two main areas. First, greater clarification of the objectives of the study and the reason why public accountants were surveyed was made in the introductory section. Second, the terminology in various sections was improved. The final version of the questionnaire stated the purpose of the research, the support provided by the ICAA, collected information on subjects' backgrounds, and captured opinions on the user practices and design features with regard to small/medium accounting packages.

The items in the questionnaire were mostly phrased "positively", i.e. expressing desirable user practices and design features. Public accountants were asked to indicate whether they agreed or disagreed that these existed among their clients of small/medium package users. The exceptions were two questions stated in the negative form but reversed for statistical analysis. Respondents expressed their opinion on the propositions on a scale of 1 (disagree) to 7 (agree).

Internal consistency of the questionnaire responses, i.e. the extent to which all of the subparts of an instrument or scale measure the same characteristics, was established through the Cronbach-Alpha technique. Table 2 
shows the alpha value for each category in the questionnaire. Some concern is reflected in the internal groupings with alpha values below 0.80 , the generally regarded satisfactory level (Sekaran, 1984). As seen, the category "Accounting Principles" showed an unsatisfactory alpha value. As a further measure of internal consistency, the inter-item correlation coefficients of the seven multiple-item categories were calculated. All the correlation coefficients with the exception of the "Accounting Principles" category were positive and significant at the 0.001 level.

Table 2: Internal consistency tests

\begin{tabular}{llll} 
Category & $\begin{array}{l}\text { Number } \\
\text { Items }\end{array}$ & $\begin{array}{l}\text { Alpha } \\
\text { Value }\end{array}$ & $\begin{array}{l}\text { Correlation } \\
\text { Coefficient }\end{array}$ \\
\hline USER PRACTICES & & & \\
Acquisition & 4 & 0.64 & $0.31^{*}$ \\
Processing \& Reporting & 4 & 0.58 & $0.26^{*}$ \\
Security & 3 & 0.60 & $0.35^{*}$ \\
Reconciliation & 3 & 0.80 & $0.58^{*}$ \\
Installation & 3 & 0.58 & $0.30^{*}$ \\
Understanding & 3 & 0.36 & $0.16^{*}$ \\
$\quad$ Category Total & 20 & & \\
DESIGN FEATURES & & & \\
Accounting Principles & 3 & -0.18 & -0.06 \\
Processing \& Reporting & 3 & 0.72 & $0.48^{*}$ \\
Audit Trail & 3 & 0.70 & $0.43^{*}$ \\
Access Control & 3 & 0.69 & $0.44^{*}$ \\
Data Control & 3 & 0.68 & $0.41^{*}$ \\
Documentation & 3 & 0.67 & $0.40^{*}$ \\
Installation & 3 & 0.47 & $0.23^{*}$ \\
$\quad$ Category Total & 21 & & \\
Survey Total & 41 & & \\
\hline * (p<.001) & \multicolumn{3}{l}{}
\end{tabular}

Since four job functions, namely Management Consulting, Business Advisory, Auditing, Accounting Services were the main contributors to the study (see Table 1), it was decided to carry out statistical analysis on the responses received from these groupings. Furthermore, concern over the internal consistency of the category "Accounting Principles" (see Table 2) caused us to exclude this category from further consideration. Below follow the results and discussion of our data analysis.

\section{RESULTS AND DISCUSSION}

To recap, in our study we asked public accountants to indicate whether they agreed or disagreed that certain user practices and design features existed among those of their clients that were small/medium package users. Respondents expressed their opinions on propositions on a scale of 1 (disagree) to 7 (agree).

\section{User practices}

Table 3 shows the mean and standard deviation (SD) for each item and each category of user practices. Categories and items within categories are ranked from the highest to the lowest means. 
Table 3: Means and standard deviations for user practices

\begin{tabular}{|c|c|c|}
\hline & Mean & SD \\
\hline INSTALLATION & 4.49 & 1.34 \\
\hline $\begin{array}{l}\text { Outside qualified support is required for the installation of packages and } \\
\text { software updates. }\end{array}$ & 5.92 & 1.02 \\
\hline System parameters are properly set up. & 4.30 & 1.42 \\
\hline $\begin{array}{l}\text { Working papers show that conversion from the old to the new system was } \\
\text { properly carried out. }\end{array}$ & 3.26 & 1.59 \\
\hline RECONCILIATIONS & 4.48 & 1.47 \\
\hline Ledgers, sub ledgers and accounts are regularly reconciled. & 4.82 & 1.51 \\
\hline $\begin{array}{l}\text { A formal procedure (e.g. checklists, reports) exists for period-end } \\
\text { processing. }\end{array}$ & 4.38 & 1.43 \\
\hline $\begin{array}{l}\text { Adequate documentation is retained as evidence that reconciliations have } \\
\text { been done. }\end{array}$ & 4.23 & 1.48 \\
\hline SECURITY & 4.38 & 1.61 \\
\hline Data and programs are secured through regular and systematic backups. & 4.91 & 1.40 \\
\hline $\begin{array}{l}\text { Access to the system is controlled, for example through the use of } \\
\text { passwords. }\end{array}$ & 4.61 & 1.76 \\
\hline $\begin{array}{l}\text { Master files are regularly checked for anomalies, for example account } \\
\text { balances are printed and verified. }\end{array}$ & 3.63 & 1.69 \\
\hline PROCESSING AND REPORTING & 4.29 & 1.50 \\
\hline $\begin{array}{l}\text { Transactions entered into the system are supported by adequate } \\
\text { documentation. }\end{array}$ & 4.72 & 1.36 \\
\hline \multirow{2}{*}{$\begin{array}{l}\text { Reports are produced to support management decision-making. } \\
\text { Input editing programs are used to ensure only valid data enter the system. }\end{array}$} & 4.67 & 1.44 \\
\hline & 3.97 & 1.58 \\
\hline $\begin{array}{l}\text { The nature of input and usage of data is defined in a data dictionary or } \\
\text { procedure manual. }\end{array}$ & 3.84 & 1.63 \\
\hline ACQUISITION & 3.92 & 1.53 \\
\hline $\begin{array}{l}\text { Packages are acquired through an evaluation and selection process (e.g. } \\
\text { Request for Proposal). }\end{array}$ & 4.24 & 1.46 \\
\hline $\begin{array}{l}\text { Users depend on modifications and customisation to packages to ensure a } \\
\text { satisfactory fit. }\end{array}$ & 4.05 & 1.63 \\
\hline Users are involved in establishing package requirements. & 4.04 & 1.61 \\
\hline $\begin{array}{l}\text { Users have the knowledge and skills to participate in the evaluation and } \\
\text { selection of packages. }\end{array}$ & 3.33 & 1.45 \\
\hline UNDERSTANDING & 3.51 & 1.43 \\
\hline $\begin{array}{l}\text { Users have ongoing access to training to overcome lack of package } \\
\text { understanding. }\end{array}$ & 3.71 & 1.46 \\
\hline $\begin{array}{l}\text { Users are able to manage packages' operations and reporting because of } \\
\text { package understanding. }\end{array}$ & 3.50 & 1.42 \\
\hline Users receive adequate training before packages are installed. & 3.32 & 1.41 \\
\hline
\end{tabular}

Of the six user practice categories, the means of four categories were above the scale midpoint of 4 and the means of two categories fell below, indicating that user practices were generally regarded satisfactory. The highest rated category was the installation of packages. However, when examining the items within the category, concern arises as to the capability of SMEs to install packages themselves. Two items attract attention; they were rated the highest and the lowest of all items respectively. The items are:

- Outside qualified support is required for the installation of packages and software updates (highest mean of 5.92).

- Working papers show that conversion from the old to the new system was properly carried out (lowest mean of 3.26). 
Three user practice categories, namely reconciliation, security, and processing and reporting, were judged to be carried out satisfactorily. There is however one concern among security practices, indicated by a low mean rating, namely

- Master files are regularly checked for anomalies, for example account balances are printed and verified (mean 3.63).

The remaining user practice categories are rated below 4 , the scale midpoint. They are acquisition and understanding. Within the former, particular concern exists for the following item:

- Users have the knowledge and skills to participate in the evaluation and selection of packages (mean 3.33).

This lack of knowledge and skill is reflected in the category of understanding where two items are lowly rated:

- Users are able to manage packages' operations and reporting because of package understanding (mean 3.50).

- Users receive adequate training before packages are installed (mean 3.32).

From analysis of responses it can be concluded that the installation phase of packages could pose problems within SMEs and a major reason for this appears to be the lack of user understanding. The lack of understanding manifests itself in inadequate training prior to the acquisition of packages which may impede SMEs' participation in the evaluation and selection of packages and subsequently not understanding packages' operations and reporting functions. The findings confirmed pervious studies, reviewed in an earlier section, that SMEs lack internal IS expertise and depend on outside support in this respect.

\section{Design features}

Table 4 provides means and standard deviations (SD) for design feature responses; categories and items are ranked in descending order of means.

Three of the six design feature categories were rated above the scale midpoint of 4 . The features offered for processing and reporting, access control and installation appear to exist in a satisfactory manner among SMEs with the exception of two items, namely

- Packages are not complex enough to require the support of vendors during installation (mean 2.90).

- A trail is kept of system users, their identity and activities (mean 3.36).

The first item relates to the installation of packages and may be one of the major reasons why SMEs rely on outside support as reported earlier.

The remaining design feature categories, audit trail, documentation and data control, were all rated below the scale midpoint. The items with the highest concerns indicate that packages appear to lack adequate control features. Control appears to be deficient in the following areas:

- Error messages provide explanations of errors and corrective actions required (mean 3.53).

- The system forces the printout or archiving of transactions before they are purged from the system (mean 3.53).

- Inbuilt controls alert users to reconcile sub ledgers with control accounts (mean 3.55).

- Packages do not permit period-end procedures to be completed until all required reports are produced (mean 3.56).

From the analysis of responses it can be concluded that SMEs find packages complex, at least in the opinion of public accountants, and hence SMEs require outside support. Furthermore, packages appear to lack a number of important control features which, considering the lack of internal IS/IT expertise in SMEs, could result in malfunctions of their accounting information processing systems. 
Table 4: Means and standard deviations for design features

\begin{tabular}{|c|c|c|}
\hline & Mean & SD \\
\hline PROCESSING AND REPORTING & 4.88 & 1.31 \\
\hline $\begin{array}{l}\text { Data input provides space to store transaction descriptions and cross- } \\
\text { references. }\end{array}$ & 5.07 & 1.26 \\
\hline Details stored in ledgers and sub ledgers enable transactions to be traced. & 5.05 & 1.21 \\
\hline Reports produced by packages support management decision-making. & 4.53 & 1.47 \\
\hline ACCESS CONTROL & 4.52 & 1.43 \\
\hline Packages contain access control mechanisms such as password control. & 5.27 & 1.19 \\
\hline $\begin{array}{l}\text { Access can be controlled to enable different persons varying degrees of } \\
\text { access to data and functions. }\end{array}$ & 4.96 & 1.43 \\
\hline A trail is kept of system users, their identity and activities. & 3.36 & 1.67 \\
\hline INSTALLATION & 4.17 & 1.35 \\
\hline Packages can be installed in modules at different intervals. & 5.15 & 1.23 \\
\hline Package modules can easily be integrated with modules installed earlier. & 4.55 & 1.46 \\
\hline $\begin{array}{l}\text { Packages are not complex enough to require the support of vendors during } \\
\text { installation. }\end{array}$ & 2.90 & 1.38 \\
\hline AUDIT TRAIL & 3.90 & $\overline{1.52}$ \\
\hline Changes to master files are recorded in audit trail & 4.14 & 1.49 \\
\hline $\begin{array}{l}\text { Audit trail details are printed to allow reference to supporting } \\
\text { documentation. }\end{array}$ & 3.99 & 1.53 \\
\hline $\begin{array}{l}\text { Packages do not permit period-end procedures to be completed until all } \\
\text { required reports are produced. }\end{array}$ & 3.56 & 1.54 \\
\hline DOCUMENTATION & 3.89 & 1.39 \\
\hline Documentation (e.g. on conversion) support the installation of packages. & 4.08 & 1.41 \\
\hline The provided documentation support the effective use of packages. & 4.05 & 1.35 \\
\hline $\begin{array}{l}\text { Error messages provide explanations of errors and corrective actions } \\
\text { required. }\end{array}$ & 3.53 & 1.43 \\
\hline DATA CONTROL & 3.83 & 1.59 \\
\hline $\begin{array}{l}\text { Warnings are provided before importing master or transaction files over } \\
\text { existing ones. }\end{array}$ & 4.44 & 1.56 \\
\hline Inbuilt controls alert users to reconcile sub ledgers with control accounts. & 3.55 & 1.69 \\
\hline $\begin{array}{l}\text { The system forces the printout or archiving of transactions before they are } \\
\text { purged from the system. }\end{array}$ & 3.53 & 1.54 \\
\hline
\end{tabular}

\section{Relationship within and between user practices and design features}

To establish the relationship of the six categories with each other, correlation coefficients were computed in three areas; they are shown in Tables 5,6 and 7.

Table 5: Correlations within user practice categories

\begin{tabular}{lllllll} 
& $(1)$ & $(2)$ & $(3)$ & $(4)$ & $(5)$ & $(6)$ \\
\hline (1) Acquisition & 1 & & & & & \\
(2) Processing\&Reporting & $.34^{* *}$ & 1 & & & & \\
(3) Security & $.33^{* *}$ & $.47^{* * *}$ & 1 & & & \\
(4) Reconciliation & $.42^{* * *}$ & $.53^{* * *}$ & $.48^{* * *}$ & 1 & & \\
(5) Installation & $.32^{* *}$ & $.56^{* * *}$ & $.48^{* * *}$ & $.61^{* * *}$ & 1 & \\
(6) Understanding & $.34^{* * *}$ & $.34^{* * *}$ & $.24^{*}$ & $.35^{* * *}$ & $.36^{* * *}$ & 1 \\
\hline
\end{tabular}

${ }^{* * *} \mathrm{p}<.001 \quad{ }^{* *} \mathrm{p}<.01{ }^{*} \mathrm{p}<.05$ 
Table 6: Correlations within design feature categories

\begin{tabular}{|c|c|c|c|c|c|c|}
\hline & $(7)$ & (8) & (9) & $(10)$ & $(11)$ & (12) \\
\hline (7) Processing\&Reporting & 1 & & & & & \\
\hline (8) Audit Trail & $.39 * * *$ & 1 & & & & \\
\hline (9) Access Control & $.32 * *$ & $.39 * * *$ & 1 & & & \\
\hline (10) Data Control & $.24^{*}$ & $.54 * * *$ & $.41^{* * *}$ & 1 & & \\
\hline (11) Documentation & $.47^{* * * *}$ & $.28^{* *}$ & $.25^{*}$ & $.44^{* * *}$ & 1 & \\
\hline (12) Installation & .06 & .10 & .06 & $.30^{* *}$ & $.33^{* *}$ & 1 \\
\hline
\end{tabular}

Table 7: Correlations between user practice and design feature categories

\begin{tabular}{lllllll}
$\begin{array}{l}\text { USER PRACTICES. IDESIGN } \\
\text { FEATURES }\end{array}$ & $\begin{array}{l}\text { Acquisi } \\
\text { tion (1) }\end{array}$ & $\begin{array}{l}\text { Proc. } \\
\text { Rep. (2) }\end{array}$ & $\begin{array}{l}\text { Security } \\
(3)\end{array}$ & $\begin{array}{l}\text { Reconcilia } \\
\text { tion(4) }\end{array}$ & $\begin{array}{l}\text { Installatio } \\
\text { n (5) }\end{array}$ & $\begin{array}{l}\text { Understand } \\
\text { ing(6) }\end{array}$ \\
\hline (7) Processing\&Reporting & .14 & $.41^{* * *}$ & $.33^{* *}$ & $.43^{* * *}$ & $.46^{* * *}$ & .13 \\
(8) Audit Trail & .12 & $.21^{*}$ & $.37^{* * *}$ & $.21^{*}$ & $.30^{* *}$ & .12 \\
(9) Access Control & .09 & $.25^{*}$ & $.39^{* * *}$ & .17 & $.35^{* * *}$ & $.21^{*}$ \\
(10) Data Control & $.22^{*}$ & -.01 & $.20^{*}$ & .17 & $.24^{*}$ & $.22^{*}$ \\
(11)Documentation & $.20^{*}$ & $.51^{* * *}$ & $.36^{* * *}$ & $.42^{* * *}$ & $.53^{* * *}$ & $.38^{* * *}$ \\
(12) Installation &. .04 & .08 & -.07 & -.05 & $.20^{*}$ & .16 \\
\hline
\end{tabular}

${ }^{* * *} \mathrm{p}<.001{ }^{* *} \mathrm{p}<.01{ }^{*} \mathrm{p}<.05$

User practice categories are all significantly correlated with each other (Table 5); strong correlations also existed among design feature categories with the exception of installation which only correlated with data control and documentation (Table 6). When correlating user practices and design features many strong relationships can be observed (Table 7). Figure 1 shows the correlations that were found between user practices and design features at the 0.01 confidence level.

The correlation coefficients between user practice and design feature categories shown on Figure 1 are all positive, i.e. they vary directly with one another. Most of the user practice categories are strongly correlated with the documentation of packages. The exception is the user practice of acquisition which does not appear on the diagram. Also missing from the diagram are the design feature categories of data control and installation as they do not correlate strongly with any of the user practice categories.

\section{IMPLICATIONS}

Public accountants are in a good position to form judgements of the use and design of packages used by their SME clients and as such are able to provide valuable input into the what can be expected from these systems. From their opinions flow a number of implications for the management of SMEs and the developers of accounting packages.

\section{Implications for SME management}

In general, public accountants rated small/medium accounting software packages as satisfactory in the majority of user practices and design features. The findings indicate that one of the key activities of small business computing, namely processing and reporting (see Gray, 1991), appears to be well handled. Similarly, reconciliations appear to be carried out satisfactorily within SMEs. Another pleasing finding is that security is exercised by users; they are supported in this respect by package features that control access to the system and to a lesser extent by features that provide control over data. By drawing the attention, however, to those areas where concerns exist that SME management can implement action to improve the success of their packaged IS.

First, SMEs need to recognise, if they have not already done so, that at present they do not appear to possess the internal expertise to install packaged software. Public accountants perceive a level of complexity within packages beyond their capabilities. This indicates, as did previous studies in the small/medium systems domain, that support from vendors is required. In addition, better working papers showing details of the conversion from the old to the new system need to be kept. 
Figure 1: Significant correlations between user practice and design feature categories

\begin{tabular}{|c|c|}
\hline Design Features & User Practices \\
\hline
\end{tabular}

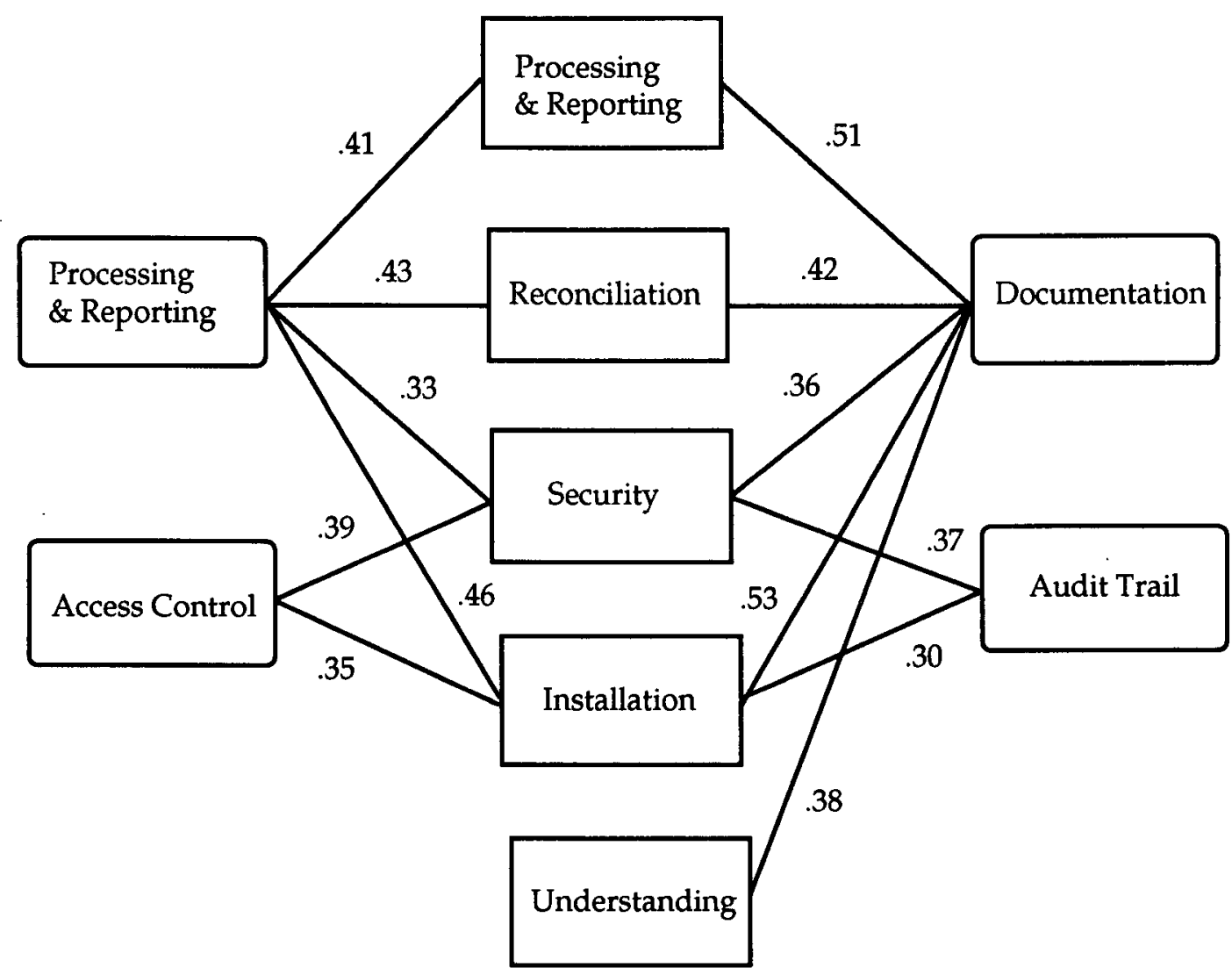

Second, SME management needs to increase users' understanding of packages. The study indicates that users should receive knowledge and skills that would enable them to participate in the evaluation and selection of packages. Furthermore, training before the packages are installed would increase their understanding and thereby their utilisation of the processing and reporting functions available in packages. Education of users would lessen the reliance placed on outside support.

The third area of concern is the lack of control features that were identified in packages. These related to inadequate explanations of errors and corrective actions required, obtaining a printout of transactions to be purged, alerting users when ledgers are not reconciled, and ensuring completion of period-end procedures. These apparent shortcomings should be addressed in conjunction with the package providers as discussed below.

\section{Implications for the developers of packaged accounting systems}

It was not the intention of this study to unearth specific deficiencies with specific packages but to gain a general understanding of the perceived strengths and weakness of packaged accounting systems. Package developers should therefore review their products and, if required, aim to improve the shortcomings of their particular product. First, a number of package control features appear to be deficient. These were identified in the preceding section and should be overcome in conjunction with the management of SMEs.

Second, packages should offer design features that give greater support to users. The documentation of packages appears to play an important role in this regard since documentation is strongly correlated with most user practices. Public accountants did not rate the documentation that currently exist very high and scope therefore exists to make improvements in this area. Particular concern related to documentation that supports the effective use of packages, viz. documentation (e.g. on conversion) to support the installation of packages, to provide error messages that explain errors and corrective actions required, and to produce a trail of system users. 
Third, SMEs apparently regard accounting packages to be complex. Vendors could reduce complexity by offering training thereby increasing their customers' understanding of their products. This should commence prior to the acquisition of the package to enable users to participate in the evaluation and selection processes and be ongoing to enable them to maximise packages' processing and reporting functions.

\section{CONCLUSION}

Research to determine the success of information systems is still agonising over the dimensions of success and as yet there is no instrument which can satisfy the requirements of all studies. Furthermore, research into the success of small business IS has only recently emerged. This study used two research variables, namely user practices and design features. They form part of Cerveny and Sanders' (1986) model to measure IS success and were selected because of their relevance to packaged accounting software which is the predominant form of IS in SMEs. Rather than canvass the opinions of SMEs or package vendors, we approached public accountants because of their independence and experience with SMEs. Whilst packages overall appear to be used and designed satisfactorily, a number of concerns were established. Management and package developers should take notice of current shortcomings in order to increase the success of Information Systems within SMEs.

\section{ACKNOWLEDGMENT}

The study was financially supported by the Institute of Chartered Accountants in Australia and jointly carried out with Ken Stevens of the Australian National University.

\section{REFERENCES}

Cerveny, R.P. \& Sanders, G.L. (1986) Implementation and Structural Variable, Information \& Management, Vol 11,pp 191-198.

Cragg, P.B. \& King, M. (1993) Small-Firm Computing: Motivators and Inhibitors, MIS Quarterly, March, pp 47-60.

DeLone, W.H. \& McLean, E.R. (1992) Information Systems Success: The Quest for the Dependent Variable, Information Systems Research, Vol 3, Iss 1, pp 60-95.

Gray, G.L. (1991) Accounting Information System Selection in Small Organizations: Incongruences between Accounting Professionals, Journal of Information Systems, Spring, pp 17-35.

Nazem, S.M. (1990) Sources of Software and Levels of Satisfaction for Small Business Computer Applications, Information \& Management, Vol 19, pp 95-100.

Ponemon, L.A. \& Nagoda II, R. J. (1990) Perceptual Variation and the Implementation of Accounting Information Systems: An Empirical Investigation, Journal of Information Systems, Spring, pp 1-14.

Saunders, C.S. \& Jones, J.W. (1992) Measuring Performance of the Information Systems Function, Journal of Management Information Systems, Vol 8, Iss 4, pp 63-82.

Sekaran, U. (1984) Research Methods for Managers A Skill-building Approach, Wiley.

Sethi, V., Hwang, K.T. \& Pegels, C. (1993) Information Technology and Organizational Performance, Information \& Management, Vol 25, pp 193-205.

Yap, C.S., Soh, C.P.P. \& Raman, K.S. (1992) Information Systems Success Factors in Small Business, Omega, Vol 20, Iss 5/6, pp 597-609.

Zeleny, M. (1982), Multiple Criteria Decision Making, New York, McGraw-Hill. 